\title{
Topological Optimization of a Mechanical System with Adaptive Convergence Criterion
}

\author{
Myriam Orquera ${ }^{(凶)}$, Sébastien Campocasso, and Dominique Millet \\ Université de Toulon, COSMER, Toulon, France \\ orquera@univ-tln.fr
}

\begin{abstract}
Topological optimization (TO) is commonly used to design a part for additive manufacturing (AM), but rarely for entire systems including several parts. How can be optimized a mechanical system in which each optimized part changes the boundary conditions? A Design method called TOMS (Topological Optimization of a Mechanical System) has been developed to take into account the variation of the boundary conditions when optimizing parts. When the using TOMS method the loops are performed until the optimization converges. The object of this article is to propose a discussion on the quantification of this convergence based on a practical case study.
\end{abstract}

Keywords: DfAM - Design for additive manufacturing · Product design · Additive manufacturing · Topological optimization

\section{Introduction}

Additive manufacturing processes allow to obtain parts or mechanical assemblies by adding material layer by layer, line by line or point by point [1]. This relatively recent manufacturing processes require new design methods due to new constraints and possibilities. Most of the methods proposed for these processes are applicable on a single part [2-4]. All these methods have in common a design framework with four steps: specification, topological optimization, volume reconstruction, validation. To perform the optimization of a part - during the second step - the CAD design and non-design spaces, the material, the boundary conditions, as well as the constraints and the optimization objective must be defined.

The articles dealing with the design of a product or a part manufactured by AM are carried out with a specific objective. For the mechanical product design proposed in [5], the objective was for example to apply AM capabilities to functionally improve the system. To achieve this, topological optimization (TO) and functional improvements were both applied on each component. Likewise Jilich et al. [6] have developed a gripper for garment handling with the objective of the diminution of part number and also functional improvement. A non-assembly additively manufactured vice was the purpose of the study presented in [7]. The necessary clearance and the most adapted orientation were chosen before applying a TO on each part. 
In all these articles, the parts have low inertia and the optimization of one of them has few influences on the mechanical behavior of the system. That is probably why the variation of the boundary conditions due to the optimization has not been taken into account.

However when the mass has an important influence on the mechanical behavior, new boundary conditions have to be taken into account. Our method called TOMS (Topological Optimization of a Mechanical System) and presented in detail in [8] is one of the firsts for designing a mechanical product taking into account this aspect. For this, optimization loops have been developed. These loops allow a product design taking into account the variations of the boundary conditions until the optimizations converge.

In this article, the TOMS method will be first briefly presented with a focus on the TO convergence. Then, the main goal of this paper is to analyze the improvements due to an adaptive convergence criterion for each part.

\section{The TOMS Method}

The Topological Optimization of a Mechanical System (TOMS) corresponds to the topological optimization of each rigid body of a mechanical product by taking into

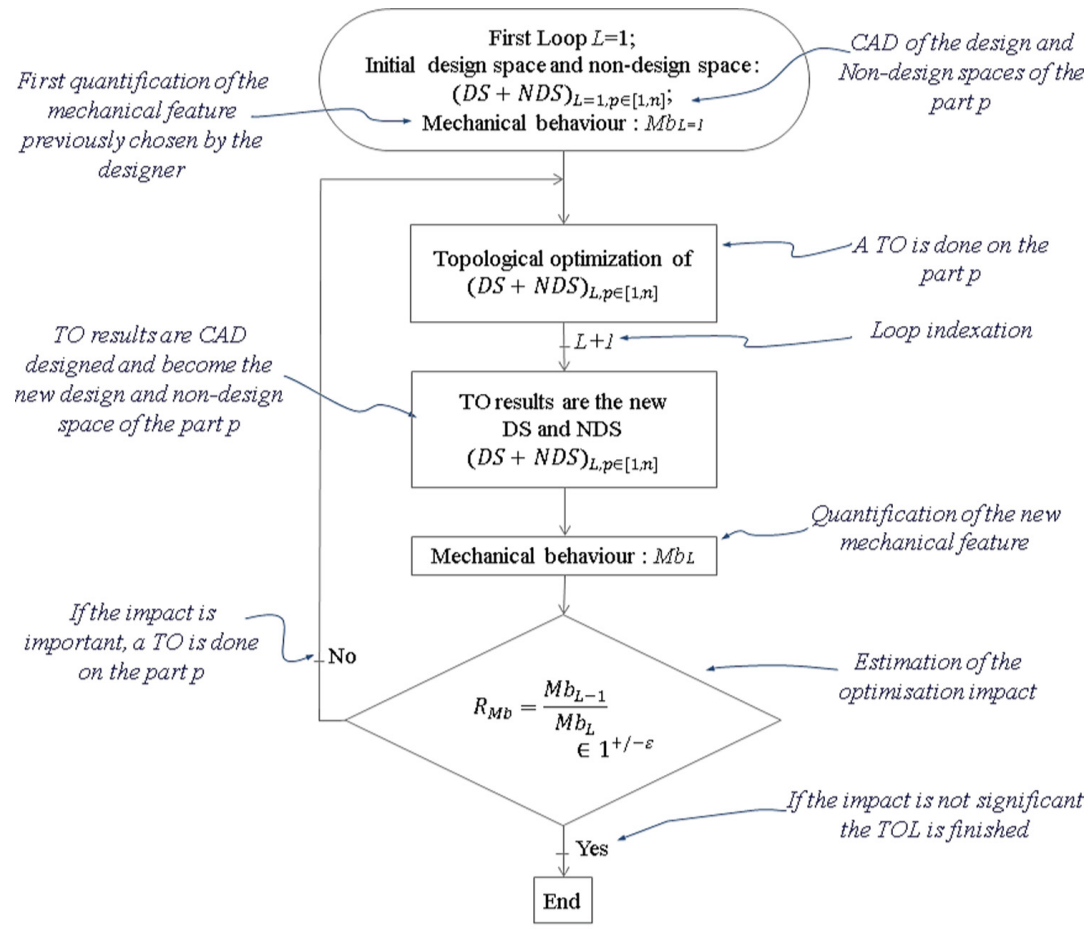

DS: Design space

NDS: Non-design pace

L: Loop number

p: Part marker

n: Total number of optimized parts

Fig. 1. Topological optimization loop (TOL) organization chart [8]. 
account the impacts of optimizations between the rigid bodies. This method was recently proposed and is more detailed in $[8,9]$.

Depending on the designer's objective, an optimization path must be chosen as well as an indicator of the mechanical behavior Mb. From the CAD of the product with its design and non-design spaces, the optimization loops denoted TOL (Topological Optimization Loops) will be applied to each of the rigid bodies until the ratio used as the variation indicator $\mathrm{R}_{\mathrm{Mb}}$ belongs to $[1-\varepsilon, 1+\varepsilon] ; \varepsilon$ is called the coefficient of convergence. The TOL and the ratio $\mathrm{R}_{\mathrm{Mb}}$ are detailed in Fig. 1.

\section{Adaptive Coefficient of Convergence $\mathrm{E}$}

The application of the TOMS method was performed on a robot arm following different optimization paths as shown the Fig. 2. The first path was carried out by optimizing first the part which has the greatest impact on the mechanical behavior Mb; while the second path began the optimization with the component which impacts the highest quantity of equations.

The initial mass of the robot is $16.2 \mathrm{~kg}$, dispatched as followed: mass of the part 1 $=6.970 \mathrm{~kg}$; mass of the part $\underline{2}=8 \mathrm{~kg}$; mass of the part $\underline{3}=1.264 \mathrm{~kg}$. The $\mathrm{R}_{\mathrm{Mb}}$ ratio is determined for the inter torque required to turn the part $\underline{1}$. The initial inter torque value is equal to 634 N.mm.

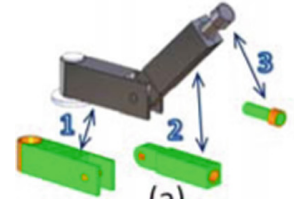

(a)

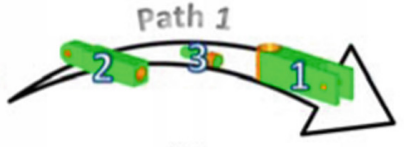

(b)

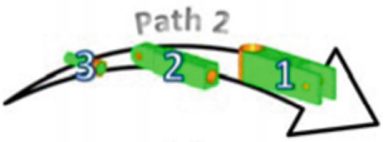

(c)

Fig. 2. (a) Robot arm with the three CAD parts, space design in green, non-design space in orange; (b) The first optimization path; (c) The second optimization path.

In this section, the value of $\varepsilon$ will be discussed for each path. $\varepsilon$ is defined as a constant that must be imposed at the beginning of the study. The lower the convergence coefficient is, the higher the impact of the optimization will be. In this article, another way to achieve optimization convergence is suggested. It consists in modifying the value of the convergence coefficient for each optimized part according to its impact on the mechanical behavior.

In the study carried out in [8], a unique value of $\varepsilon$ was set at 0.1 , which leads to carry out a certain number of optimization loops on the parts as shown in Table 1 for path 1 and 2.

For the first path, in order to identified the part which has the greatest impact on the mechanical behavior $\mathrm{Mb}$, a reduced sensitivity coefficient $\mathrm{S}^{*}$ (see Table 2) of the chosen mechanical behavior was determined for each part $i$. The convergence coefficient could vary depending on this reduced sensitivity coefficient $S^{*}$. Indeed, the higher the coefficient $S^{*}$ is, the lower $\varepsilon$ must be. The part which has the higher reduced sensitivity 
Table 1. Results of the TOMS method on the robot arm for the path 1 and 2 with $\varepsilon=0.1$.

\begin{tabular}{|c|c|c|c|c|c|c|c|c|c|c|c|c|}
\hline \multirow{3}{*}{$\begin{array}{l}\text { Part } n^{\circ} \\
\text { Loop } n^{\circ}\end{array}$} & \multicolumn{6}{|c|}{ Path 1} & \multicolumn{6}{|c|}{ Path 2} \\
\hline & \multicolumn{2}{|c|}{ Part 2} & \multicolumn{2}{|l|}{ Part 3} & \multicolumn{2}{|c|}{ Part 1} & \multicolumn{2}{|l|}{ Part 3} & \multicolumn{2}{|l|}{ Part 2} & \multicolumn{2}{|l|}{ Part 1} \\
\hline & 1 & 2 & 1 & 2 & 1 & 2 & 1 & 2 & 1 & 2 & 1 & 2 \\
\hline $\mathrm{R}_{\mathrm{Mb}}$ & 2.12 & 1.05 & 2.43 & 1.04 & 1.23 & 1.02 & 1.36 & 1.01 & 3.84 & 1.08 & 1.23 & 1.04 \\
\hline $\begin{array}{l}\text { Product } \\
\text { mass }(\mathrm{kg})\end{array}$ & 9.26 & 8.97 & 7.98 & 7.95 & 2.45 & 2.11 & 15.21 & 15.1 & 8.11 & 7.93 & 2.39 & 1.87 \\
\hline $\begin{array}{l}\text { Part mass } \\
(\mathrm{g})\end{array}$ & 1055 & 768 & 274 & 246 & 1466 & 1130 & 274 & 246 & 926 & 749 & 1434 & 912 \\
\hline $\begin{array}{l}\text { Inter torque } \\
(\text { N.mm) }\end{array}$ & 299 & 285 & 117 & 112 & 91 & 89 & 466 & 461 & 120 & 112 & 91 & 88 \\
\hline $\begin{array}{l}\text { CPU Time } \\
\text { (h:min) }\end{array}$ & $8: 37$ & $0: 26$ & $19: 28$ & $0: 45$ & $8: 58$ & 1:02 & $19: 28$ & $0: 45$ & $10: 20$ & $0: 32$ & $7: 48$ & 1:09 \\
\hline $\begin{array}{l}\text { Total Time } \\
\text { (h:min) }\end{array}$ & $39: 19$ & & & & & & 40:04 & & & & & \\
\hline
\end{tabular}

coefficient is set as the reference part; its sensitivity coefficient is denoted $S_{0}^{*}$ and is determined as shown the Eq. (1). The coefficient of convergence is set to 0.1 for the reference part and is denoted $\varepsilon_{0}$. For the robot arm, the reference part is the part 2 .

$$
S_{0}^{*}=\max \left(S_{\mathrm{i}}^{*}\right)
$$

Then, the $\varepsilon_{i}^{\text {path } 1}$ of the part $i$ is then inversely proportional to the percentage of the impact on the mechanical behavior Mb as shown in the Eq. (2).

$$
\varepsilon_{i}^{p a t h 1}=\varepsilon_{0} \cdot \frac{S_{0}^{*}}{S_{i}^{*}}
$$

Analogous reasoning can be established for the second path which begins the optimization of the component which impacts the highest number of equations. The part 3 has feature characteristics in nine equations. The Eq. (3) shows how to determinate $\varepsilon_{i}^{\text {path } 2}$ for each part $i$ using the number of equation $n_{i}$. In the Table 2 the value of $\varepsilon_{i}^{\text {path } 2}$ are determined for each part.

$$
\varepsilon_{i}^{p a t h 2}=\varepsilon_{0} \cdot \frac{\max \left(n_{i}\right)}{n_{i}}
$$

For paths 1 and 2, the last optimized part, which is the support 1 , will only undergo one optimization if setting $\varepsilon$ higher than 0.3 . The shaded columns of the Table 1 show which loops won't be done for a adaptive $\varepsilon$. In the Table 3, the gains and losses due to this new value of the convergence coefficient in terms of time, mass and torque are summarized. It can be noticed that the total mass obtained with a variable $\varepsilon$ is higher thans that obtained for an $\varepsilon=0.1$ whatever the path. This is due to one less topological optimization on one or more parts.

For an on-board system used in aerospace, the addition of mass savings will represent a financial gain during operation. In this case, the value of the coefficient of convergence should be close to 0.1 . 
Table 2. Adaptive values of the coefficient of convergence for each part, for the path 1 and 2.

\begin{tabular}{|c|c|c|c|c|c|c|c|}
\hline & Path 1 & & & & Path 2 & & \\
\hline Part $^{\circ}$ & Part 2 & Part 3 & Part 1 & Part $^{\circ}$ & Part 3 & Part 2 & Part 1 \\
\hline Characteristic $\mathrm{Ci}$ & $\mathrm{m}_{2}$ & $\mathrm{~m}_{3}$ & $I_{1(0,0)}$ & \multirow{3}{*}{$\begin{array}{l}\text { Number of } \\
\text { equations } n_{i} \\
\varepsilon_{j}^{\text {path2 }}\end{array}$} & \multirow[b]{2}{*}{9} & \multirow[b]{2}{*}{6} & \multirow[b]{2}{*}{1} \\
\hline $\mathrm{S}^{*}\left(M_{b} / C_{i}\right)=C_{i} \cdot \frac{\partial M_{b}}{\partial C_{i}}$ & 0.34 & 0.21 & 0.03 & & & & \\
\hline$\varepsilon_{i}^{p a t h 1}$ & $\varepsilon_{0}=0.1$ & 0.16 & 0.7 & & $\varepsilon_{0}=0.1$ & 0.15 & 0.9 \\
\hline
\end{tabular}

In the article [8], a third path where all part are simultaneously optimized was also proposed. It can be noted that, for this path, the variation of the convergence coefficient is not applicable.

Table 3. Gain and loss compared to $\varepsilon=0.1$.

\begin{tabular}{l|l|l}
\hline & Path 1 & Path 2 \\
\hline Mass & $13.6 \%$ loss & $21.5 \%$ loss \\
\hline Inter torque (N.mm) & $2.25 \%$ loss & $3.4 \%$ loss \\
\hline Total CPU time (h:min) & $2.6 \%$ gain & $2.5 \%$ gain \\
\hline
\end{tabular}

\section{Conclusion and Perspectives}

In this article the TOMS method has been briefly presented. This method is useful to topologically optimize a multi-component mechanical system. A loop denoted TOL is used with regard to the modification of the boundary conditions due to the TO. The TOL is applied on a rigid body until the optimizations converge. The coefficient of convergence has an impact on the result as it is explained in this article. The consequences of the choice of the coefficient of convergence - depending on the use of the system - are shown. For the case study of this article, the adaptive convergence coefficient for each part allows to obtain a little saving of time. However, for a product with a large number of parts, the saving in study time could be much greater. Indeed, study time can be saved on parts with a low impact on the mechanical behavior without losing the gain of mass.

In perspective, a generalization of the choice of the coefficient of convergence will allow the designer to overcome this step.

\section{References}

1. Thompson, M.K., et al.: Design for additive manufacturing: trends, opportunities, considerations, and constraints. CIRP Ann. Manuf. Technol. 65, 737-760 (2016) 
2. Tomlin, M., Meyer, J.: Topology optimization of an additive layer manufactured (ALM) aerospace part. In: Proceeding of the 7th Altair CAE Technology Conference, pp. 1-9 (2011)

3. Kumke, M., Watschke, H., Vietor, T.: A new methodological framework for design for additive manufacturing. Virtual Phys. Prototyp. 11(1), 3-19 (2016)

4. Weis, P., Großmann, A., Clemen, C., Mittelstedt, C.: Optimization and re-design of a metallic riveting tool for selective laser melting - a case study. Addit. Manuf. 31, 100892 (2019)

5. Orquéra, M., Campocasso, S., Millet, D.: Design for additive manufacturing method for a mechanical system downsizing. Procedia CIRP 60, 223-228 (2017)

6. Jilich, M., Frascio, M., Avalle, M., Zoppi, M.: Development of a gripper for garment handling designed for additive manufacturing. Proc. Inst. Mech. Eng. Part C J. Mech. Eng. Sci. 095440621985776 (2019)

7. Sossou, G., Demoly, F., Montavon, G., Gomes, S.: An additive manufacturing oriented design approach to mechanical assemblies. J. Comput. Des. Eng. 5(1), 3-18 (2018)

8. Orquéra, M., Campocasso, S., Millet, D.: Some principles to optimise an additively manufactured multi-component product. J. Eng. Des. 31(4), 219-240 (2020)

9. Orquéra, M.: Conception pour la fabrication additive: Approche méthodologique pour les systèmes mécaniques multi-corps, Université de Toulon (2019)

Open Access This chapter is licensed under the terms of the Creative Commons Attribution 4.0 International License (http://creativecommons.org/licenses/by/4.0/), which permits use, sharing, adaptation, distribution and reproduction in any medium or format, as long as you give appropriate credit to the original author(s) and the source, provide a link to the Creative Commons license and indicate if changes were made.

The images or other third party material in this chapter are included in the chapter's Creative Commons license, unless indicated otherwise in a credit line to the material. If material is not included in the chapter's Creative Commons license and your intended use is not permitted by statutory regulation or exceeds the permitted use, you will need to obtain permission directly from the copyright holder.

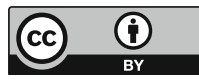

